\title{
Blood Supply to the Conducting System of the Heart in Complex Types of Congenital Heart Defects
}

\section{Spirina GA*}

Department of Human Anatomy, Ural State Medical University, Yekaterinburg, Russian Federation, Russia

*Corresponding Author: Spirina GA, Department of Human Anatomy, Ural State Medical University, Yekaterinburg, Russian Federation, Russia.

DOI: $10.31080 /$ ASMS.2020.04.0566
Received: January 24, 2020

Published: February 14, 2020

(c) All rights are reserved by Spirina GA.

\begin{abstract}
Blood supply to the conducting system of the heart in complex types of malformations was studied on 44 samples including the hearts of fetuses and children of the first three years. Generally accepted morphological methods were used. The similarities and differences in the blood supply to the conducting system with congenital heart defects and normal development are revealed.
\end{abstract}

Keywords: Heart; Congenital Malformations; Conducting System

\section{Introduction}

Among the morphological problems of Congenital Heart Defects (CHD) specific attention should be given to study of blood supply to its conducting system. Knowledge of this issue is necessary for successful surgical correction of this pathology and investigating the causes of the development of postoperative conduction disorders [1-13].

\section{Aim of work}

Study of the blood supply of conducting system of the heart in complex types of CHD.

\section{Material and Methods}

Studying of blood supply of an atrioventricular node, the eponymous bundle and right bundle, left bundle was carried out on 44 specimens including hearts of fetuses and children of the first three years having CHD such as the full form of common atrioventricular canal, Tetralogy of Fallot (TOF), hypoplastic left heart syndrome, the combination of interventricular septal defect with common arterial truncus. For blood supply examination to the atrioventricular section of the conducting system of the heart the following procedures were used: injection of cardiac arteries by radiographic and colored masses; radiography; dissection; light scattering; preparation of serial histological sections. Blood supply to the conducting system of the heart was studied on 50 specimens of the hearts of fetuses and children of a similar age with normal development as the control.

\section{Results and Discussion}

According to information received, the middle-right and right types of its blood supply with CHD predominate. There are similarities between vascularization of the conducting system with a normally developed heart and with CHD. Blood supply to the conducting system of the heart is carried out simultaneously by the branches of both coronary arteries (Table 1).

\begin{tabular}{|l|l|l|}
\hline № & $\begin{array}{l}\text { Sources of blood supply of the atrio- } \\
\text { ventricular node }\end{array}$ & $\begin{array}{l}\text { Frequency of } \\
\text { observations,\% }\end{array}$ \\
\hline 1. & Atrioventricular nodal artery only & 65,5 \\
\hline 2. & $\begin{array}{l}\text { Artery of the atrioventricular node } \\
\text { and branches of the posterior atrial } \\
\text { arteries }\end{array}$ & 12,8 \\
\hline 3. & $\begin{array}{l}\text { Artery of the atrioventricular node and } \\
\text { branches of the anterior atrial arteries }\end{array}$ & 12,8 \\
\hline 4. & $\begin{array}{l}\text { Branches of anterior atrial arteries } \\
\text { only }\end{array}$ & 6,4 \\
\hline 5. & $\begin{array}{l}\text { Artery of the atrioventricular node } \\
\text { and branches of the posterior superior } \\
\text { artery of the interventricular septum }\end{array}$ & 2,6 \\
\hline
\end{tabular}

Table 1: Frequency of observations of sources of blood supply to the atrioventricular node (\%). 
Arterial blood supply to the atrioventricular node with CHD changes drastically. The level of involvement of the branches of the first anterior atrial arteries in the vascularization of the node with CHD has increased by 5 times on average. This circumstance can be explained by the "hypertrophy" of the atrial arteries and their branches because of the increased load on them by CHD. The artery walls are more extensible, and the arteries that are responsible for their blood supply are exposed to dynamic blood pressure. Due to the anatomical localization, the artery of the atrioventricular node experiences less impact during atrial systole, which leads to less development of its branches in conditions of impaired hemodynamics. In case of CHD and in a normally formed heart, the branch of the artery of the atrioventricular node passes predominantly through the atrioventricular node (70\% of specimens). A normally formed heart, like one with CHD, has blood supply to the atrioventricular node and to the eponymous bundle carried out by different branches of the coronary arteries, which is explained by their emergence as separate structures with subsequent connection with each other. If there is CHD, an artery of the atrioventricular node arises from an artery that determines the type of blood supply to the heart. In certain specimens with the full form of the common atrioventricular canal, the coronary artery does not form a "U-shaped" bend at the point of branching from it to the atrioventricular node. As we know, with this type of congenital heart disease, the atrioventricular node is located in the initial (embryonic) position in the rearmost wall of the right atrium. The central fibrous body is not formed. The ventricular part of the atrioventricular bundle is located on the muscular crest on the left side of the sinus part of the interventricular septum. The bend occurrence in the right or left coronary arteries is associated with the migration of the atrioventricular node. The intensity of the lateral branches from the artery of the atrioventricular node to the heart partitions is determined by the hemodynamic features with CHD. There is a pronounced variability in the nature of branching and distribution of the branches of the arteries of the atrioventricular node. The occurrence of large branches from the artery of the atrioventricular node to the posterior wall of the right atrium and the myocardium of the interventricular septum was detected by the Fallot tetrad. In the separate specimens, the artery of the atrioventricular node is rotated in the cranial direction. Newborns and infants with CHD have tortuosity of the branches of the blood vessels of the atrioventricular node and bundle, including the branch passing through the node (Figure 1 and 2). Nowadays it is considered that the evidence of the coronary arteries and their branches is characterized by the degree of coronary accommodation and serves as an indicator of their functional activity. Apparently, an increase in the tortuosity of the artery of the atrioventricular node and its branches with CHD helps to reduce the strength of the pulse push, to establish a correspondence between the amount of blood and the volume of the vascular bed. The lowest number of nutritive sources has a penetrating part of the atrioventricular bundle. In the blood supply to its ventricular part, the branches of the arteries of the atrioventricular node or, together with them, the first anterior septal arteries or only the last ones participate. The most variable in the number and variety of nutritive sources is the vascularization of the anatomical bifurcation of the atrioventricular bundle. if there is a CHD, the nature of the branching of small vessels that fit the ventricular part of the atrioventricular bundle and its legs is the same as a normally formed heart. The number of small vessels increases in the area of atrioventricular node localization and the bundle of the same name. The ratio of the artery of the atrioventricular node to the defect edge is determined by the location of the latter. The defect is located anterior and upward from the artery of the atrioventricular node with the full form of the open atrioventricular canal. If there is a secondary atrial septal defect, the artery of the atrioventricular node passes under its lower edge. In the presence of congenital heart disease, the source of blood supply to the anatomical bifurcation of the atrioventricular bundle, the initial parts of the right and left legs is the first anterior septal branch of the anterior interventricular artery. In 50\% of congenital heart disease, the three anterior septal branches are equally developed and participate equally in the blood supply to the right and left legs of the bundle, about $36.3 \%$ of the specimens with this pathology have the first anterior septal artery predominating in diameter and $13.7 \%$ observations have the second anterior septal artery predominating. In the presence of the full form of the common atrioventricular canal there were noted both the same development of the first three anterior septal branches and the predominance of the first of them. In TOF cases the largest anterior septal branches are the first or second. If there is a CHD, the first septal artery, which is the largest in diameter, supplies the anatomical bifurcation of the atrioventricular bundle, the right and left legs. With the equal development of the first three anterior septal arteries, the first of them feeds the anatomical bifurcation of the atrioventricular bundle, the proximal parts of the right and left legs, the second branch - the middle part of the legs, the third - their distal parts. Due to the position of the ventricular 
part of the atrioventricular bundle on the left side of the muscular crest of the sinus part of the interventricular septum, the branches of the first anterior septal artery that carry out its blood supply are displaced to the left side of the septum.

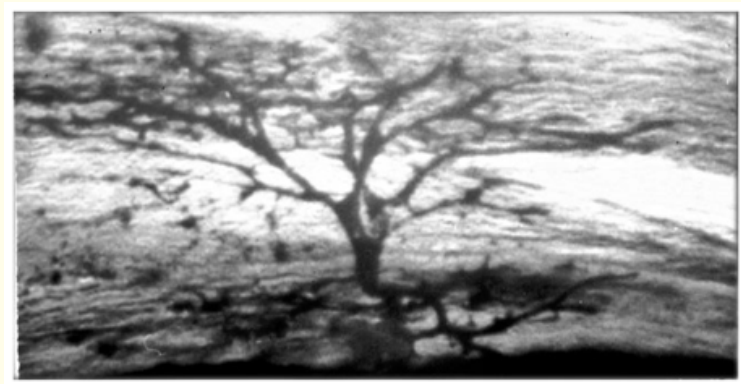

Figure 1: Branching of small blood vessels going to the atrioventricular bundle with CHD.

Injection of coronary arteries with mass of Herot with enlightenment. Microphoto 8x4.

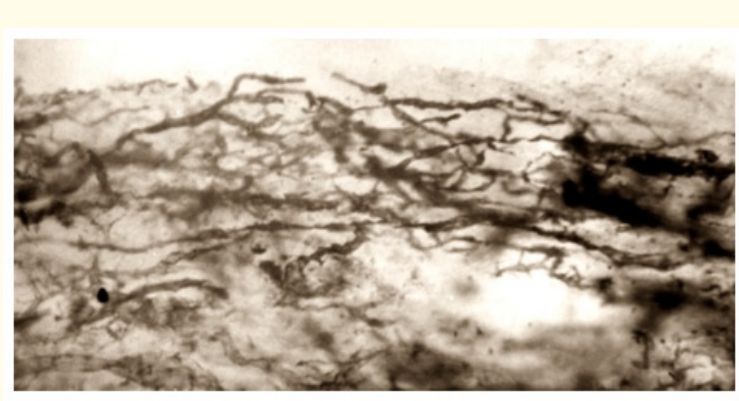

Figure 2: Curved forms of small blood vessels in the atrioventricular bundle with CHD.

Injection of coronary arteries with mass of Herot with enlightenment. Microphoto 8x4.

\section{Conclusions}

1. If there is a congenital heart defect, the degree of participation in the blood supply of the atrioventricular node of the first anterior atrial arteries increases by a factor of 4 to 5 .

2. It was noted that the sinuous artery of the atrioventricular node is enlarged.
3. The severity of the lateral branches from the artery of the atrioventricular node to the septum of the heart is determined by the peculiarities of hemodynamic changes in congenital heart defects.

4. According to the left-side position of the ventricular part of the atrioventricular bundle (TOF), the blood supplying branches of the first anterior septal artery are displaced to the left side of the interventricular septum.

5. In the presence of the full form of the open atrioventricular canal, the presence of an U-shaped bend of the coronary artery at the point of departure of the atrioventricular artery from it is inconstant, which is apparently due to the localization of the atrioventricular node in the embryonic position.

\section{Bibliography}

1. Anderson RH., et al. "Vascular supply of the junctional area The conduction". function and clinical implication / Ed. H. J. J. Wellens, K.I. Lie, M. J. Janse. - Philadelphia: Lea Febiger (1976): 263-268.

2. Anderson RH., et al. "Morphology of congenital heart disease". Angiocardiographic, echocardiographic and surgical correlates/ Ed. C. House. - London, (1983): 149.

3. Bharati S., et al. "Cardiac surgery and the conduction system". - New-York - Chichester - Toronto - Singapore: John Wiley Sons (1983): 107.

4. Clarke JA. "An X-ray microscopic study of the arterial supply to the conducting system of the human heart". British Heart Journal 27.6 (1965): 879-883.

5. Dabizzi RP., et al. "Distribution and anomalies of coronary arteries in tetralogy of Fallot". Circulation 61.1 (1980): 95-102.

6. Davies MJ. "Pathology of conducting tissue of the heart". - London: Butterworths Co (1971): 286.

7. Dickinson DF., et al. "Variations in morphology of the ventricular septal defect and disposition of the atrioventricular conduction tissues in Tetralogy of Fallot". The Journal of Thoracic and Cardiovascular Surgery 30.4 (1982): 243-249.

8. Feldt RH., et al. "The atrioventricular conduction system in persistent common atrioventricular cannal defect". Circulation 42.3 (1970): 437-444.

9. Goor DA and Lillehei CW. "Congenital malformations of the heart / Embryology, anatomy and operative considerations. New York: Grune a. Stratton (1975): 324. 
10. Ho SY and Anderson RH. "Conduction tissue in congenital heart surgery". World Journal of Surgery 9.4 (1985): 550-567.

11. Latham RA and Anderson RH. "Anatomical variations in atrioventricular conduction system with reference to ventricular septal defects". British Heart Journal 34.1 (1972): 185-190.

12. Lev M. "The architecture of conduction system in congenital heart disease. I. Common atrioventricular orifice". Archives of Pathology 65 (1958): 174-191.

13. Meng CCL., et al. "Coronary artery distribution in tetralogy of Fallot”. The Archives of Surgery 90 (1965): 363-366.

\section{Assets from publication with us}

- Prompt Acknowledgement after receiving the article

- Thorough Double blinded peer review

- Rapid Publication

- Issue of Publication Certificate

- High visibility of your Published work

Website: https://www.actascientific.com/

Submit Article: https://www.actascientific.com/submission.php

Email us: editor@actascientific.com

Contact us: +919182824667 